\title{
Technoeconomical Analysis of Macrocell and Femtocell Based HetNet under Different Deployment Constraints
}

\author{
Syed Fahad Yunas, Waqas H. Ansari, and Mikko Valkama \\ Department of Electronics and Communications Engineering, Tampere University of Technology, 33720 Tampere, Finland \\ Correspondence should be addressed to Syed Fahad Yunas; syed.yunas@tut.fi
}

Received 4 January 2016; Revised 24 April 2016; Accepted 29 May 2016

Academic Editor: Changqiao Xu

Copyright ( 2016 Syed Fahad Yunas et al. This is an open access article distributed under the Creative Commons Attribution License, which permits unrestricted use, distribution, and reproduction in any medium, provided the original work is properly cited.

\begin{abstract}
Ultradense deployment of small cells is being considered as one of the key flavors of the emerging $5 \mathrm{G}$ cellular networks to address the future data capacity challenges. A large share of these deployments will be indoor, as this is the arena where the majority of the data traffic is believed to originate from in the future. Indoor small cell solutions (e.g., femtocell or WiFi) are well positioned for delivering superior indoor coverage and capacity. However, due to relatively smaller coverage footprint compared to traditional macrocells, a very dense deployment of small cells will be needed in order to have a ubiquitous indoor coverage. Such dense deployment triggers cost and energy efficiency concerns for mobile operators. In this paper, we analyze and compare the technoeconomic performance of two deployment strategies: homogeneous macrocellular densification and heterogeneous macro-femto deployment strategy, from an indoor service provisioning perspective. Particularly, we analyze and contrast the performance of macro-femto based deployment, with varying femtocell market penetration rate and under different femtocell backhaul connectivity constraints, with that of homogeneous macrocellular densification. The results indicate superior performance of indoor femtocell based deployment as compared to macrocellular-only densification, due to better indoor coverage, radio channel conditions, and high degree of spatial reuse.
\end{abstract}

\section{Introduction}

Keeping in view the drastic increase in the mobile subscribers' footprint, it is commonly predicted that the amount of mobile data traffic will increase by 1000 -fold in the near future $[1,2]$. According to a recent report by the International Telecommunications Union (ITU), there will be approximately 25 billion connected devices by year 2020 [3]. New advancements are being made in the existing network infrastructure to support the exponential increase in the future capacity demands while seeking to keep the costs and energy consumption feasible.

The fundamental mechanisms to increase the capacity of a network are (i) improving the spectral efficiency with advanced modulation and coding techniques, (ii) improving the interference conditions within a cell by using advanced antenna technology (e.g., beamforming) or novel radio resource management methods, (iii) increasing the bandwidth of the radio communication channel, (iv) increasing the number of links between a transmitter and a receiver through the use of spatial multiplexing technology (e.g., $M I M O)$, and (v) adopting aggressive frequency reuse, that is, reusing the same radio resources several times over a given area by deploying more base stations. The last technique has been shown to provide significant network capacity gains since the dawn of cellular networks [4].

Ultradense network deployment has been identified as one of the key network evolution strategies to address the 1000x capacity problem. Unfortunately, the network infrastructure costs also increase with the number of base stations. For any mobile operator, the cost of deploying and operating a network is a key concern that has to be managed in order to stay competitive in the market. Hence, operators look for network deployment solutions that offer increased network capacity with lower costs and energy consumption.

In mobile services industry, it has been long presumed that $70 \%$ to $85 \%$ of the overall mobile traffic is generated by indoor users [5, 6]. However, it has also been reported that most of the complaints related to poor coverage come from 
the indoor users [5]. The reason is attributed to the traditional approach used by mobile operators in providing coverage to the indoor users through outdoor deployments, mainly macrocells. Outdoor signals incur high losses when penetrating into the indoor environment through the external walls. Traditionally, the values have been in the range of $5 \mathrm{~dB}-15 \mathrm{~dB}$. However, recently increased awareness of global warming and the resulting requirements to save energy and cut down $\mathrm{CO}_{2}$ emissions has led to several initiatives being taken at the international level. One such initiative by EU Commission requires "improving the thermal insulation of the new residential and commercial buildings by 2020 " [7]. The use of new modern building materials to improve the thermal insulation has consequently negative impact on the radio signals. In a recently reported study $[8,9]$, the external wall penetration loss for modern town houses has been reported to be up to $35 \mathrm{~dB}$. We believe that these penetration loss values will continue to increase with further advancement in building insulation materials. To overcome this issue, operators may densify their existing network, that is, increasing the number of outdoor base stations or deploying indoor small cell solutions (e.g., femtocells or WiFi). In this paper, the deployment of indoor femtocells partially comes from the requirement to provide indoor coverage to the town houses with modern building materials, which otherwise would be difficult to achieve with outdoor deployment solutions. Due to being located indoors, femtocells are well positioned to address the issue of poor indoor coverage. However, due to their small coverage area, they are needed to be deployed in an ultradense fashion to provide seamless coverage throughout the whole indoor environment. Thus, not only coverage is improved, but also the capacity is enhanced due to extreme spatial reuse. Nevertheless the ultradense deployment of indoor femtocells triggers cost and energy usage concerns for the mobile operators.

Moreover, unlike traditional deployment solutions (e.g., macrocell or microcells) that have a dedicated carrier grade backhaul, femtocells utilize the end users broadband Internet service, for example, ADSL (Asymmetric Digital Subscriber Line), cable modem, or FTTH (Fiber to the Home), to connect to an operator's core network. As such, the achievable data throughput is thus limited by the connection speed of the broadband connection, which in turn impacts the offered capacity.

A report [10] published by Akamai Technologies in the second quarter (Q2) of the year 2015 reveals the average data rates of Internet broadband connections around the world. Table 1 enlists the top ten average data rates by country, followed by the average global data rate.

In this paper, we investigate two mobile network evolution strategies: (a) homogeneous macrocellular densification and (b) macro-femto based heterogeneous network (HetNet) deployment. The deployment strategies are particularly evaluated from an indoor service provisioning perspective in a suburban type environment. For the femtocell backhaul we consider different backhaul connectivity speeds, ranging from low Internet connection (4 Mbps) to ultrahigh speed broadband connection (100 Mbps). For the macrocell sites, a dedicated carrier grade backhaul connection to each site
TABLE 1: Global average broadband connection speeds [10].

\begin{tabular}{lcc}
\hline Number & Country/region & $\begin{array}{c}\text { Q2 '15 } \\
\text { Avg. (Mbps) }\end{array}$ \\
\hline 1 & South Korea & 23.1 \\
2 & Hong Kong & 17.0 \\
3 & Japan & 16.4 \\
4 & Sweden & 16.1 \\
5 & Switzerland & 15.6 \\
6 & Netherlands & 15.2 \\
7 & Latvia & 14.3 \\
8 & Norway & 14.2 \\
9 & Finland & 14.0 \\
10 & Czech Republic & 13.9 \\
\hline- & Global & 5.1 \\
\hline
\end{tabular}

is assumed with no backhaul bottleneck (for simplicity), although in reality the backhaul connection speed of macrocells is also limited. Apart from the backhaul limitation, we also consider different penetration rates for indoor femtocells. We then compare the corresponding network capacity and energy-efficiency and cost-efficiency of macro-femto HetNet with different backhaul limitations and deployment penetration rates to homogeneous macrocellular densification strategy. In order to overcome the high wall penetration losses, we particularly investigate an extreme deployment scenario, where a dedicated indoor femtocell is deployed in every suburban town house (100\% femtocell penetration), to provide coverage and capacity. We examine whether such deployment will be energy-efficient and cost-efficient as compared to traditional macrocellular deployment. The main objective of this research work is to provide deep insight into the technoeconomical aspects of different mobile network deployment and densification solutions that can assist mobile operators in deciding the best network evolution strategy for their mobile network in the future. We specifically analyze and address the following questions related to mobile network evolution:

(i) Which layer (macro or femto) should the mobile operator densify in order to meet the future capacity demands?

(ii) Does femtocell backhaul limitation have significant impacts on the overall capacity and cost-and energyefficiency performance of macro-femto network?

(iii) Which network evolution strategy yields the most significant network capacity gains and what are the corresponding deployment costs? Is it ultradense deployment of indoor small cells or increasing the operating bandwidth for outdoor legacy (macrocell) infrastructure?

\section{Related Work}

Several studies have been published in recent years related to modeling and performance evaluation of heterogeneous wireless networks (HetNet). The publications deal with different aspects of HetNets ranging from capacity evaluation 


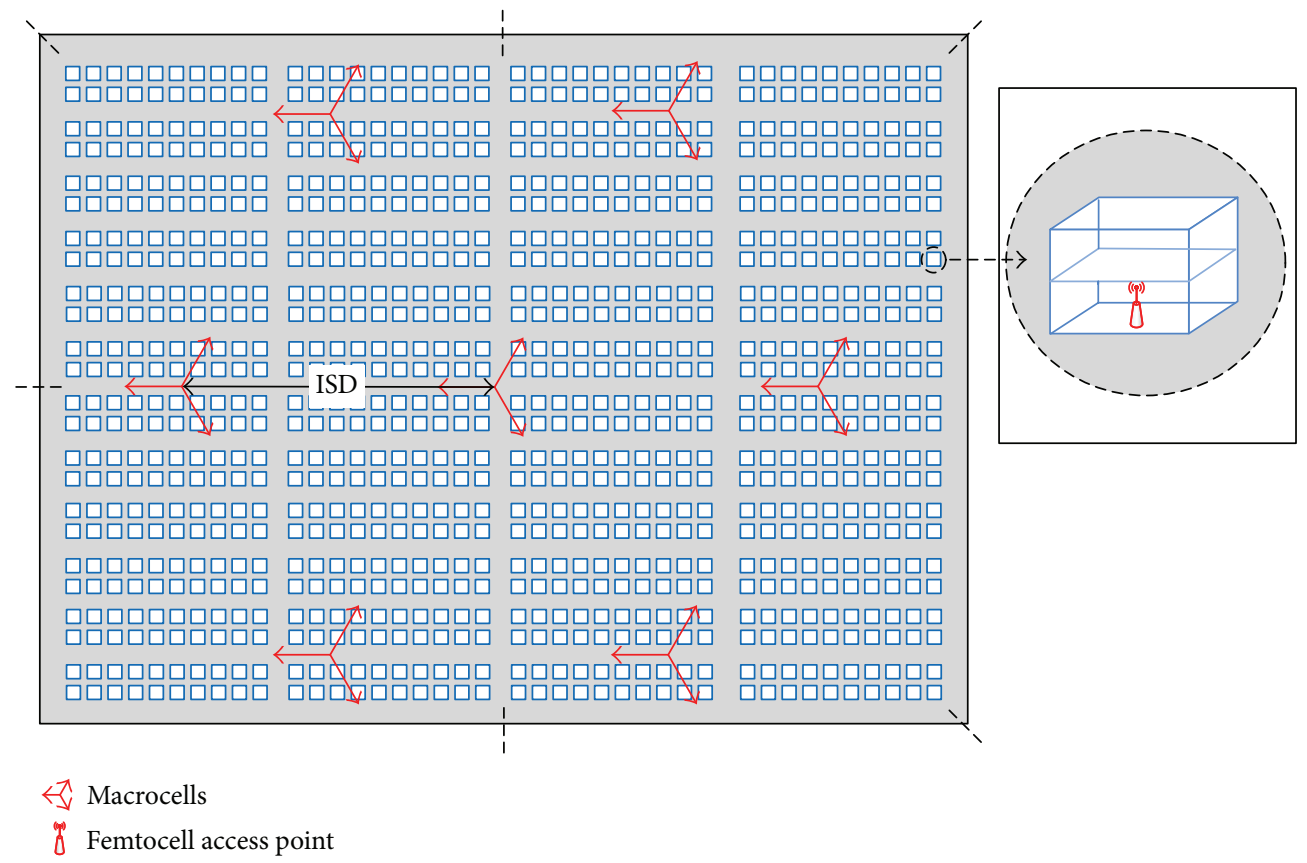

FIGURE 1: Suburban scenario used in the analysis. The 3-sector macrocell sites are deployed using clover-leaf (modified hexagonal) layout, with certain intersite distance (ISD). The position and orientation of the macrocell sectors are illustrated by red arrows. Only one tier of macrocells is shown, whereas the analysis considers two tiers of macrocell interferers. The femtocells are only deployed on the ground floor level.

to energy-efficiency assessment and cost-benefit analysis. The area spectral efficiency performance of a two-tier macrofemto HetNet has been evaluated in [11]. The authors conclude that significant capacity gains can be achieved by introducing low cost and low power femtocells in the existing macrocellular network. In [12], the capacity-cost comparison of pure macrocellular and femtocell solutions has been carried out for low and high demand levels. The results revealed that the deployment of femtocells in existing macrocellular network is only cost-effective strategy when new macrosites are required to be deployed. A similar study comparing the performance of homogeneous macro-only network and heterogeneous macro-femto network in terms of capacity and cost- and energy-efficiency for indoor service provisioning, considering different backhaul options, has been carried out in [13]. The authors report that backhaul solutions play a key role in the total cost of a mobile network, especially for exponential rising capacity demand of the future. For high capacity demand, the fiber-optic based backhaul solution is the most energy- and cost-efficient as compared to microwave backhaul option. The economic assessment of introducing femtocells into an existing macrocellular based LTE network, with open access and closed access femto mode, is investigated in [14]. In [15], a feasibility study has been done on the multiradio access technology carrier aggregation (multi-RAT CA) based on macrocellular and WiFi HetNet. The paper highlights some open research problems related to integrated LTE-advanced and WiFi practical deployment. The impact of femtocell deployment on the energy-efficiency in a cochannel macro-femto network is investigated in [16]. The findings in the paper indicate that significant savings in the energy consumption can be achieved in macro-femto network, compared to macro-only network, when the capacity demand is high. In [17], the technical and economical aspects of different deployment strategies based on pure macrocellular deployment, pure microcellular deployment, and indoor femtocell based ultradense HetNet deployment have been evaluated from indoor service provisioning perspective. It was concluded that the dense deployment of indoor femtocells is a feasible network evolutionary pathway to meet the future indoor capacity requirements. The paper assumed an unlimited backhaul connectivity for the indoor femtocells.

This paper further extends the previous study reported in [17] and analyzes the impact of varying femtocell market penetration rate and backhaul limitations on the overall performance of macro-femto HetNet. Moreover, the performance of macro-femto HetNet is compared with a homogeneous macrocellular deployment with different carrier bandwidths ( $5 \mathrm{MHz}, 40 \mathrm{MHz}$, and $100 \mathrm{MHz}$ ). The analysis is done from an indoor service provisioning perspective.

\section{System Model and Assumptions}

3.1. Scenario Description. The deployment strategies are evaluated in a model suburban type environment comprising residential blocks. Each block consists of 20 town houses arranged in a grid pattern, as illustrated in Figure 1. A town house has dimensions of $10 \mathrm{~m} \times 10 \mathrm{~m}$, with $5 \mathrm{~m}$ height, and comprises 2 floors. The indoor floor plan in each house is modeled as an open area with no interior walls; that is, the radio signals inside the house encounter no obstructions except for the penetration loss due to exterior walls and 
TABLE 2: Cell densities for different deployment scenarios.

\begin{tabular}{|c|c|c|c|c|}
\hline \multirow{2}{*}{ Deployment strategy } & \multirow{2}{*}{ Femtocell penetration rate (\%) } & \multicolumn{3}{|c|}{ Cell density (cells $\left./ \mathrm{km}^{2}\right)$} \\
\hline & & ISD $1732 \mathrm{~m}$ & ISD $866 \mathrm{~m}$ & ISD $433 \mathrm{~m}$ \\
\hline Homogeneous: macro-only & 0 & 3.5 & 13.9 & 55.4 \\
\hline \multirow{8}{*}{ Heterogeneous: macro-femto } & 5 & 160 & 171 & 212 \\
\hline & 10 & 316 & 327 & 368 \\
\hline & 15 & 472 & 483 & 524 \\
\hline & 20 & 629 & 640 & 680 \\
\hline & 25 & 785 & 796 & 837 \\
\hline & 50 & 1566 & 1577 & 1618 \\
\hline & 75 & 2347 & 2358 & 2399 \\
\hline & 100 & 3129 & 3140 & 3180 \\
\hline
\end{tabular}

ceiling/floor, as shown in Figure 1. The outdoor-to-indoor wall penetration loss is set at $30 \mathrm{~dB}$, which is in line with the recent measurements reported for modern town houses in IMT (2100 MHz) band [9]. The floor/ceiling penetration loss is selected to be $4 \mathrm{~dB}$. In the considered scenario, there are approximately 3125 residential houses per $\mathrm{km}^{2}$.

3.2. Deployment Strategies. For the technoeconomical analysis and comparison, we consider the following two deployment strategies for indoor service provisioning.

3.2.1. Homogeneous Macro-Only Deployment. In this strategy the indoor locations in the suburban area are served by outdoor macrocellular layer. For the macrocellular deployment, a clover-leaf (modified hexagon) layout is used as the basis [18]. The clover-leaf layout defines the relative site location and sector orientation, as shown by the red arrows in Figure 1. The macrocell density depends on the cell dominance area, which is specified by the intersite distance (ISD). The cell dominance area is defined as the best server region where a cell provides the strongest coverage compared to the rest of the neighboring cells. Assuming a regular hexagon cell, the dominance area of a macrocell, $A_{\text {cell }}$, is given by

$$
A_{\text {cell }}\left(\mathrm{km}^{2}\right)=\frac{\sqrt{3}}{6}\left(\bar{d}_{\text {site }}\right)^{2}
$$

where $\bar{d}_{\text {site }}$ is the average intersite distance $(\mathrm{m})$. In this paper we consider three intersite distances: ISD $1732 \mathrm{~m}$ (baseline), ISD $866 \mathrm{~m}$, and ISD $433 \mathrm{~m}$. The corresponding cell densities for the considered ISDs are given in Table 2.

In order to improve the cell edge coverage and mitigate the intercell and intracell interference, the macrocell sector antennas are "electrically" downtilted such that the antenna boresight points at the cell border region $[19,20]$. As such, the electrical tilt angle depends on maximum cell range, $r_{\text {cell }}(\mathrm{m})$. For a three-sector hexagonal cell site, $r_{\text {cell }}$ is approximately $0.67 \times \bar{d}_{\text {site }}$. Knowing the macro sector antenna height $\left(h_{\text {Macro }}\right)$, the user equipment (UE) antenna height $\left(h_{\mathrm{UE}}\right)$, and the cell range $\left(r_{\text {cell }}\right)$, the tilt angle can be calculated geometrically as

$$
\phi_{\text {etilt }}=\arctan \left(\frac{h_{\mathrm{Macro}}-h_{\mathrm{UE}}}{r_{\text {cell }}}\right)+\frac{\phi_{-3 \mathrm{~dB}}}{2} .
$$

In (2), $\phi_{-3 \mathrm{~dB}}$ is the vertical $3 \mathrm{~dB}$ beamwidth of the antenna, which must be accounted for when calculating the downtilt angle [21].

3.2.2. Heterogeneous Macro-Femto Deployment. In this strategy, a multilayer network is formed by deploying femtocells within the coverage area of macrocells. Both macro and femto layers share the same carrier frequency (cochannel deployment). Moreover, the femtocell access point (FAP) density, for each macro ISD, is varied from 5\% (nominal femtocell deployment) to $100 \%$ (ultradense deployment; i.e., every house has a separate indoor femtocell deployed). It is pertinent to mention that the maximum number of femtocells deployed per residential house is set to 1. Furthermore, for simplicity, no intercell and intralayer coordination is assumed. Table 2 gives the combined macro-femto cell densities for different femtocell penetration rates.

3.3. Propagation Modeling. The radio propagation channel is modeled using deterministic Dominant Path Prediction Model (DPM) [22]. The Dominant Path Prediction Model is similar to traditional ray-optical models; however, instead of computing all the ray paths between a transmitter and a receiver (which is typical in ray tracing models), the DPM model computes only those paths that contribute $90 \%$ of the total signal energy at the receiver. This method has been shown to reduce the computation time significantly compared to traditional ray tracing models, while keeping the accuracy nearly identical [23].

The path loss, $L(\mathrm{~dB})$, in DPM model is approximated using the following equation [22]:

$$
L=20 \log _{10}\left(\frac{4 \pi}{\lambda}\right)+10 p \log _{10}(d)+\sum_{i=0}^{k} f(\varphi, i)+\Omega,
$$

where $d$ is the distance between a transmitter and a receiver, $p$ is the path loss exponent, $\lambda$ is the wave length (depending upon the carrier frequency), and $f(\varphi, i)$ is a function to compute the interaction loss in $(\mathrm{dB})$ due to change in direction of wave propagation (the wave changes direction due to diffraction phenomenon). The diffraction loss depends on $\varphi$ which is the angle between the former direction and the new direction of propagation. $\Omega$ is the wave-guiding 
TABLE 3: Path loss exponent values for suburban environment.

\begin{tabular}{lc}
\hline \multicolumn{2}{c}{ Suburban outdoor } \\
Line-of-Sight (LOS) before breakpoint & 2.0 \\
Line-of-Sight (LOS) after breakpoint & 2.2 \\
Obstructed Line-of-Sight (OLOS) before breakpoint & 3.5 \\
Obstructed Line-of-Sight (OLOS) after breakpoint & 4.0 \\
\hline \multicolumn{2}{c}{ Suburban indoor } \\
Line-of-Sight (LOS) & 2.0 \\
Obstructed Line-of-Sight (OLOS) & 4.0 \\
\hline
\end{tabular}

(tunneling) effect for considering the effect of reflections along the path. Further details about the propagation model and its working principle can be found in [22-24]. The path loss exponent values used in the simulations, for the suburban outdoor and indoor environment, are listed in Table 3.

3.4. Antenna Model. The 3-sector macrocell sites employ directional antennas. The sector antenna is modeled using an extended 3 GPP antenna model proposed in [25].

The gain in the $2 \mathrm{D}$ azimuth plane, $G_{\mathrm{az}}$, is calculated as follows:

$$
G_{\mathrm{az}}(\varphi)=-\min \left[12\left(\frac{\varphi}{\mathrm{HPBW}_{\mathrm{az}}}\right)^{2}, \mathrm{FBR}\right]+G_{m},
$$

where $\varphi,-180^{\circ} \leq \varphi \leq 180^{\circ}$, is the azimuth angle relative to the antenna boresight, $\mathrm{HPBW}_{\mathrm{az}}$ is the azimuth half-power beamwidth $\left({ }^{\circ}\right)$, FBR is the front-to-back ratio $(\mathrm{dB})$, and $G_{m}$ is the maximum gain of the antenna in the antenna boresight $(\mathrm{dBi})$. follows:

The gain in the $2 \mathrm{D}$ zenith plane, $G_{\mathrm{zen}}$, is calculated as

$$
G_{\text {zen }}(\phi)=-\max \left[-12\left(\frac{\phi-\phi_{\text {etilt }}}{\text { HPBW }_{\text {zen }}}\right)^{2}, \text { SLL }\right],
$$

where $\phi,-90^{\circ} \leq \phi \leq 90^{\circ}$, is the negative zenith angle relative to azimuth plane (i.e., $\phi=-90^{\circ}$ is the upward plane relative to the antenna boresight, $\phi=0^{\circ}$ is along the antenna boresight, and $\phi=90^{\circ}$ is the downward plane relative to the boresight), $\phi_{\text {etilt }}$ is the electrical downtilt angle $\left(^{\circ}\right), \mathrm{HPBW}_{\text {zen }}$ is the zenith half-power beamwidth $\left({ }^{\circ}\right)$, and SLL is the side lobe level $\left({ }^{\circ}\right)$ relative to the maximum gain. The antenna parameter values for macrocell were adopted from [25]. The femtocell access points employ omnidirectional antennas. Table 4 lists the general parameters used in the simulations.

\section{Analysis Methodology and Performance Metrics}

4.1. Overview of the Analysis Methodology. In this section, we highlight the key analysis methodology used for the performance analysis of the different deployment strategies.

(i) The study is done based on a technology-neutral approach; that is, the analysis is not bound to any specific radio access technology. As such, the cell and

\begin{tabular}{|c|c|c|c|}
\hline Parameter & Unit & Macrocell & Femtocell \\
\hline $\begin{array}{l}\text { Operating } \\
\text { frequency }\end{array}$ & $\mathrm{GHz}$ & \multicolumn{2}{|c|}{2.1} \\
\hline $\begin{array}{l}\text { Carrier } \\
\text { bandwidth(s) }\end{array}$ & $\mathrm{MHz}$ & \multicolumn{2}{|c|}{$5,40,100$} \\
\hline Transmit power & $\mathrm{dBm}$ & 43 & 20 \\
\hline BS antenna type & & Directional & Omnidirectional \\
\hline $\begin{array}{l}\text { BS antenna } \\
\text { beamwidth, } \\
\mathrm{HPBW}_{h / v}\end{array}$ & $\circ$ & $65^{\circ} / 6^{\circ}$ & $360^{\circ} / 90^{\circ}$ \\
\hline $\begin{array}{l}\text { BS antenna gain, } \\
G_{m}\end{array}$ & $\mathrm{dBi}$ & 18 & 2.2 \\
\hline UE antenna type & & \multicolumn{2}{|c|}{ Half-wave dipole } \\
\hline UE antenna gain & $\mathrm{dBi}$ & \multicolumn{2}{|c|}{2.2} \\
\hline $\begin{array}{l}\text { BS antenna height, } \\
h_{\mathrm{BS}}\end{array}$ & $\mathrm{m}$ & 30 & 2 \\
\hline $\begin{array}{l}\text { UE antenna height, } \\
h_{\mathrm{MS}}\end{array}$ & $\mathrm{m}$ & \multicolumn{2}{|c|}{2 (relative to floor level) } \\
\hline $\begin{array}{l}\text { Receiver noise } \\
\text { figure }\end{array}$ & $\mathrm{dB}$ & \multicolumn{2}{|c|}{9} \\
\hline $\begin{array}{l}\text { Backhaul } \\
\text { connectivity } \\
\text { constraint }\end{array}$ & Mbps & No constraint & 4,16 , and 100 \\
\hline \multicolumn{4}{|c|}{ Simulation environment } \\
\hline $\begin{array}{l}\text { Propagation } \\
\text { scenario }\end{array}$ & & \multicolumn{2}{|c|}{ Suburban } \\
\hline Propagation model & & \multicolumn{2}{|c|}{$\begin{array}{c}\text { Dominant Path Prediction } \\
\text { Model [22] }\end{array}$} \\
\hline $\begin{array}{l}\text { Building } \\
\text { dimensions }\end{array}$ & $\mathrm{m}$ & \multicolumn{2}{|c|}{$10 \times 10$} \\
\hline Building height & $\mathrm{m}$ & \multicolumn{2}{|c|}{5} \\
\hline Indoor floor plan & & \multicolumn{2}{|c|}{ Open space } \\
\hline $\begin{array}{l}\text { External wall } \\
\text { penetration loss }\end{array}$ & $\mathrm{dB}$ & \multicolumn{2}{|c|}{30} \\
\hline $\begin{array}{l}\text { Ceiling/floor } \\
\text { penetration loss }\end{array}$ & $\mathrm{dB}$ & \multicolumn{2}{|c|}{4} \\
\hline
\end{tabular}

TABLE 4: General simulation parameters.

network level capacities are modeled using Shannon capacity bound based on the prevailing signal to interference and noise ratio (SINR) characteristics.

(ii) The network is assumed to operate in a full load condition in which all the radio elements (both macrocells and femtocells) are transmitting at their maximum power setting. This represents a worst case scenario and also a typical methodology that is used for network capacity dimensioning. As such the different deployment solutions are thus pushed to their ultimate limits in a systematic manner.

(iii) The distribution of receiver points across all the buildings (floors) is uniform. These receiver points are adopted to be able to analyze the pointwise network capacity (i.e., network capacity per receiver point) within the cell area and hence capture the overall cell level capacity statistics. 
(iv) For the placement of femtocells, in a heterogeneous deployment scenario, we use Monte-Carlo approach. During each run, the femtocells are randomly deployed in the residential houses (with the condition maximum one femtocell per house) and then simulated for received signal strength. The distribution of femtocells over the given area is uniform. Furthermore, in order to get statistically reliable results, we run the Monte-Carlo simulation 100 times.

For clarity, it is to be acknowledged that this analysis approach does not explicitly consider any radio resource management (RRM) aspects in a multiuser network but simply seeks to quantify the maximum available network capacity that the different considered deployment strategies can offer when pushed to their limits.

4.2. Cell and Network Area Capacity. The average cell level capacity, $\bar{C}_{\text {cell }}$, under given radio propagation environment and interference conditions within a cell area, is estimated using the Shannon capacity bound as

$$
\bar{C}_{\text {cell }}=\left\langle W \cdot \log _{2}(1+\Gamma)\right\rangle,
$$

where $W$ is the carrier bandwidth $(\mathrm{MHz}), \Gamma$ refers to the instantaneous signal to interference and noise ratio (SINR), which defines the radio channel conditions, while $\langle\cdot\rangle$ denotes averaging across all receiver points. By reusing the same spectral resources over an area of $1 \mathrm{~km}^{2}$ (i.e., by deploying multiple base stations per $1 \mathrm{~km}^{2}$ ), the average network area capacity, $\bar{C}_{\text {net }}$, due to spatial reuse is approximated as

$$
\bar{C}_{\text {net }}=\rho_{\text {cell }} \bar{C}_{\text {cell }} \text {, }
$$

where $\rho_{\text {cell }}$ is the cell density (number of cells per $\mathrm{km}^{2}$ ).

From (7), we can see that the average network area capacity depends on the average cell level capacity and the spatial reuse rate (i.e., cell density per $\mathrm{km}^{2}$ ). The average cell level capacity is determined by the distribution of $\Gamma$, as evident from (6), which largely depends upon the deployed network architecture. Depending on the underlying deployment strategy, a UE may experience interference from only cochannel macrolayer (in case of homogeneous macrodeployment) or from both macro- and femtolayers (in case of heterogeneous macro-femto cochannel deployment), as shown in Figure 2. This is elaborated more as follows.

4.2.1. Homogeneous Macro-Only Deployment. In homogeneous macro-only deployment scenario, a UE within a macrocell experiences interference from other cochannel macro cells. The SINR in such a scenario is given by

$$
\Gamma_{i}=\frac{S_{i}}{\sum_{j} I_{j, i}+P_{o}},
$$

where $S_{i}$ is the received signal power of the serving macrocell at $i$ th UE. $I_{j, i}$ is the received power of the $j$ th cochannel macrocell interferer at $i$ th $\mathrm{UE}$, and $P_{o}$ refers to the receiver noise floor, which depends on the operating bandwidth and UE receiver noise figure.

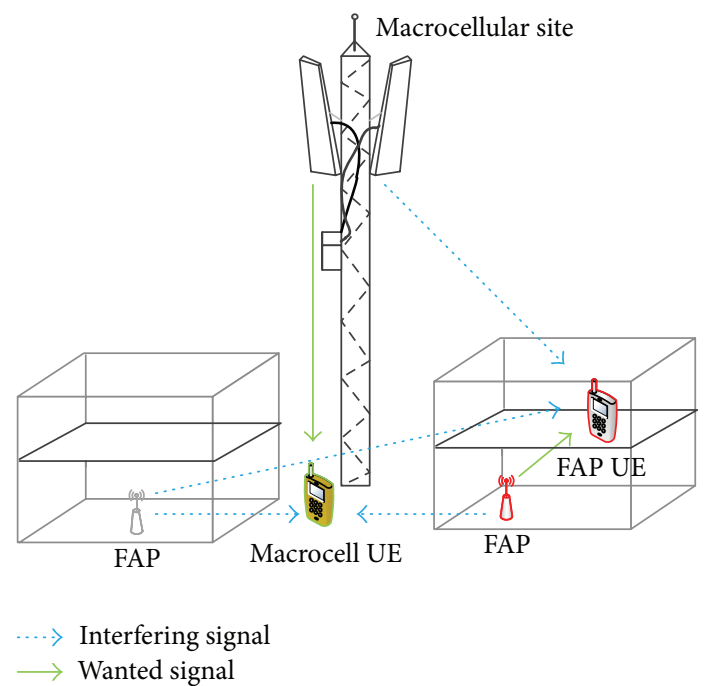

FIGURE 2: Radio channel (interference) conditions experienced by UEs in a cochannel macro-femto network (other macrocell tiers are not shown).

4.2.2. Heterogeneous Macro-Femto Deployment. For the cochannel macro-femto heterogeneous deployment scenario, there are two UE cases: (a) a UE connected to a femtocell access point and (b) a UE connected to the macrocell. The SINR in both cases is given by

$$
\begin{aligned}
\text { (a) }: \Gamma_{i}^{\text {Femto }} & =\frac{S_{i}^{\text {Femto }}}{\sum_{j} I_{j, i}^{\text {Macro }}+\sum_{k} I_{k, i}^{\text {Femto }}+P_{o}}, \\
\text { (b) }: \Gamma_{i}^{\text {Macro }} & =\frac{S_{i}^{\text {Macro }}}{\sum_{j} I_{j, i}^{\text {Macro }}+\sum_{k} I_{k, i}^{\text {Femto }}+P_{o}},
\end{aligned}
$$

where $\Gamma_{i}^{\text {Femto }}$ and $\Gamma_{i}^{\text {Macro }}$ denote the instantaneous SINR conditions experienced at the $i$ th UE connected to the femtocell access point and macrocell, respectively. In both cases, the total interference experienced by the $i$ th UE is the summation of received signal powers coming from other cochannel macro- and femtocells.

4.3. Energy-Efficiency. For analyzing the energy-efficiency of both homogeneous macro-only and heterogeneous macrofemto deployments, we use the same methodology as described in $[17,26,27]$. In this paper, the energy-efficiency of a network is defined as the aggregate data rate that is achievable while consuming a given power, for example, $1 \mathrm{~kW}$. This methodology is appropriate for assessing the energyefficiency of a network operating under full load condition [28]. As such, the network energy-efficiency, $E_{\text {eff }}$, is given by:

$$
E_{\text {eff }}=\frac{\bar{C}_{\text {net }}}{P_{\text {area }}},
$$

where $\bar{C}_{\text {net }}$ is the average network area capacity and $P_{\text {area }}$ is the area power consumption of the access network elements (base stations) within a nominal $1 \mathrm{~km}^{2}$ geographical area. The 
area power consumption, $P_{\text {area }}$, of a wireless access network depends on the dominance area of a base station site, $A_{\text {site, }}$, and the individual power consumption of a base station site, $P_{\mathrm{BS}}$, and is given by [28-31]

$$
P_{\text {area }}\left(\mathrm{W} / \mathrm{km}^{2}\right)=\frac{P_{\mathrm{BS}}}{A_{\text {site }}} .
$$

In general, the main power consuming equipment at a base station site is the base transceiver station (BTS), which supports transmission and reception to and from the user equipment (UE). A BTS of a macrocell site and a femtocell access point vary significantly in the internal architecture. This difference stems from the clearly different deployment purpose of macrocell (providing outdoor wide area coverage) and femtocell access points (covering small indoor locations). This has significant impact on their overall power consumption and hence should be accurately estimated.

4.3.1. Power Consumption Model for Macrocell Base Station. The power consumption for a macrocellular base station is estimated using power consumption model proposed in [29]. The model takes into account the impact of base station site components as well as the impact of hourly network load. As such the power consumption of a macro base station site, $P_{\mathrm{BS}}^{\mathrm{Macro}}$, is given by

$$
P_{\mathrm{BS}}^{\mathrm{Macro}}(\mathrm{W})=P_{\text {const }}+P_{\text {load }} \cdot F,
$$

where $P_{\text {const }}$ is the total load-independent power contribution stemming from rectifier, fiber-optic link for backhaul connectivity, and site air conditioning unit. $P_{\text {load }}$, in turn, is the total load-dependent power consumption share stemming from power amplifier, transceiver, and digital signal processing units. $F$ is the load factor, varying between 0 (no load) and 1 (high/peak load). For the analysis, we consider $F=1$, that is, full load. Table 5 summarizes the input parameters for the macro base station power consumption model. The parameters are approximate values taken from $[17,29]$. It is pertinent to note that the power amplifier (PA) efficiency for macrocell has been assumed to be $45 \%$, which is in line with recently reported efficiencies (35\% to 65\%) for Doherty PA architectures, with advanced signal conditioning algorithms, operating at peak load $[28,32,33]$. As a result, the power consumption of PA during peak load is $44 \mathrm{~W}$. Moreover, we assume an outdoor pole mounted macro BTS, which does not require air conditioning [34]. Hence, the power consumption of air conditioning unit is assumed to be 0 watts in this study. Based on the parameters in Table 5, the total power consumption of a macro base station site, operating in a full load condition, is be evaluated to be approximately $1 \mathrm{~kW}$.

4.3.2. Femtocell Access Point (FAP) Power Consumption Model. The power consumption of a femtocell access point, $P_{\mathrm{BS}}^{\mathrm{Femto}}$, is estimated using the power consumption model proposed in [35]:

$$
P_{\mathrm{BS}}^{\mathrm{Femto}}(\mathrm{W})=P_{\mathrm{MP}}+P_{\mathrm{FPGA}}+P_{\mathrm{TRX}}+P_{\mathrm{Amp}} \text {, }
$$

TABLE 5: Input parameters for the macro BS power consumption model.

\begin{tabular}{lcc}
\hline Component/equipment & Unit & Value \\
\hline Number of sectors & Watts & 3 \\
Transmit power at the antenna & Watts & 100 \\
$\begin{array}{l}\text { Power consumption of DSP card } \\
\text { Power amplifier efficiency }\end{array}$ & $\%$ & 45 \\
$\begin{array}{l}\text { Power consumption of } \\
\text { transceiver }\end{array}$ & Watts & 100 \\
$\begin{array}{l}\text { Power consumption of rectifier } \\
\text { Power consumption of }\end{array}$ & Watts & 100 \\
fiber-optic link unit & Watts & 7.5 \\
\hline
\end{tabular}

TABLE 6: Input parameters for the femtocell BS power consumption model.

\begin{tabular}{lcc}
\hline Component/equipment & Unit & Value \\
\hline $\begin{array}{l}\text { Transmit power at the antenna, } \\
P_{\mathrm{TX}}\end{array}$ & Watts & 0.1 \\
$\begin{array}{l}\text { Power amplifier efficiency, } \eta_{\mathrm{Amp}} \\
\begin{array}{l}\text { Power consumption of } \\
\text { transceiver, } P_{\mathrm{TRX}}\end{array}\end{array}$ & $\%$ & 20 \\
$\begin{array}{l}\text { Power consumption of } \\
\text { microprocessor, } P_{\mathrm{MP}}\end{array}$ & Watts & 1.7 \\
$\begin{array}{l}\text { Power consumption of FPGA, } \\
P_{\mathrm{FPGA}}\end{array}$ & Watts & 3.2 \\
\hline
\end{tabular}

where $P_{\mathrm{MP}}$ is the power consumption from the microprocessor unit, $P_{\mathrm{FPGA}}$ is the power consumption contribution from field programmable gate array, $P_{\mathrm{TRX}}$ is the power consumption of radio transceiver unit, and $P_{\text {Amp }}$ is the power consumption of power amplifier. As the femtocell technology targets the consumer market segment, the internal electronic components of the access points, especially the PA, are not necessarily as power efficient as those of macrocellular base stations to keep the FAP price tag within affordable range. Thus, the PA efficiency in FAP's is relatively quite low compared to macrocell PA efficiency. For the analysis a 20\% power amplifier efficiency has been assumed for the femtocell AP, which results in power amplifier consumption of $0.5 \mathrm{~W}$. Table 6 lists power consumption of different components of FAP, taken from [35]. Based on the parameters in Table 6, the total power consumption of a femtocell base station is estimated to be approximately $10 \mathrm{~W}$.

4.4. Cost-Efficiency. Mobile operators strive to provide maximum coverage and capacity to their customers while keeping the deployment and operational costs as minimum as possible. Cost-benefit analysis, thus, provides a general picture of the cost structure of an evolutionary pathway for a certain technology or system and whether or not it is a feasible option for investment. For assessing the cost viability of homogeneous and heterogeneous deployment strategies, we use the cost-analysis methodology described in $[17,26]$. As 
TABLE 7: CAPEX and OPEX costs for different base station types.

\begin{tabular}{lcc}
\hline CAPEX (initial costs) & Macrocell BS & Femtocell AP \\
\hline Base station equipment & $10 \mathrm{k} €$ & $0.1 \mathrm{k} €$ \\
Site deployment cost & $5 \mathrm{k} €$ & $0 \mathrm{k} €$ \\
\hline Total CAPEX & $15 \mathrm{k} €$ & $0.1 \mathrm{k} €$ \\
\hline OPEX (running costs) & Macrocell BS & Femtocell AP \\
\hline Site rent (lease) & $5 \mathrm{k} € /$ year & $0 \mathrm{k} € /$ year \\
Backhaul cost & $5.5 \mathrm{k} € /$ year & $0.5 \mathrm{k} € /$ year \\
Operation and maintenance & $3.5 \mathrm{k} € /$ year & $0 \mathrm{k} € /$ year \\
\hline Total OPEX & $14 \mathrm{k} € /$ year & $0.5 \mathrm{k} € /$ year \\
\hline
\end{tabular}

such, the cost-efficiency, $C_{\text {eff }}$, is defined as the amount of bits transferred per unit cost. Mathematically,

$$
C_{\text {eff }}=\frac{\bar{C}_{\text {net }}}{T_{\text {cost } / \mathrm{km}^{2}}},
$$

where $\bar{C}_{\text {net }}$ is the average network area capacity given by (7) and $T_{\operatorname{cost} / \mathrm{km}^{2}}$ is the total network deployment cost normalized to $1 \mathrm{~km}^{2}$ area. The cost of deploying a cellular network can be broadly divided into two types: (i) CAPEX (capital expenditure) and (ii) OPEX (operational expenditure). The CAPEX is the investment cost usually considered during the initial network roll-out phase or when the network is upgraded and includes costs related to radio BTS, transmission equipment, antennas, cables, and site build-out and installation cost. OPEX, on the other hand, constitutes accumulated running costs of the network and consists of site rental, backhaul lease, and operation and maintenance (OA\&M) of the network. The total cost structure of a mobile operator is dominated by OPEX [36], which spans over the life-period of the network. The "total cost per base station" is estimated in terms of net present value (NPV), which is simply found by summing up the discounted annual cash flow expenditures for a given study period (in years) $[36,37]$. Mathematically,

$$
\mathrm{BS}_{\mathrm{NPV}}=\sum_{i=0}^{Y} \frac{c_{i}}{(1+r)^{i}},
$$

where $Y$ is the study period in years (we assume 8 years for base stations value depreciation), $c_{i}$ is the total annual expenditure per base station (which includes running cost and may include investment cost) in the ith year, and $r$ is the discount rate set at $10 \%$. Furthermore, we assume that, for each deployment strategy, the whole network is deployed in the first year only. Hence, when calculating the NPV of the base station, the CAPEX is only considered in the first year while in the following years the accumulated cost from operating expenditures is only considered. For simplicity we ignore the additional costs related to radio network planning, core network, and marketing costs.

Similar to power consumption, the cost structure for the macro base station site and femtocell access point also varies significantly because of the internal base station system architecture as well as the deployment setup. Table 7 gives the approximate values for various cost items for macrocell cell site and femtocell access point (AP). The cost items are divided into CAPEX and OPEX. Moreover, the cost values for macrocell base station have been adopted from [38]. The cost items for a femtocell access point, which is mainly targeted towards the residential consumer market, are selected to be comparable to commercially available WiFi access point. From operational expenses point of view, the only running cost incurred in operating a femtocell is the backhaul connectivity, which we assume to be via residential broadband connection (the annual rate is based on the flat rate assumption of $40 €$ per month). Using the values in Table 7, the total cost per base station, in net present value, over the 8 -year period and at discount rate of $10 \%$ is calculated to be $104 \mathrm{k} €$ for a 3 -sector macrocell base station and $3.3 \mathrm{k} €$ for femtocell.

\section{Results and Analysis}

Based on the analysis methodology described in the previous section, we now evaluate and analyze the technoeconomical performance and behavior of the investigated deployment strategies. For performance benchmarking purposes, we consider homogeneous macrodeployment with ISD $1732 \mathrm{~m}$ as the baseline. The outcome of this section will provide us with technoeconomical insight into the network evolution strategy that will be best suited for mobile operators to address the exponentially rising indoor capacity demand.

5.1. Coverage and Interference Analysis. In general, received useful signal power and SINR are the most important performance indicators that provide primary information on how well a system/network is performing under given radio channel conditions. From the overall cell site capacity perspective, the performance at the cell edge is of significance as these regions, due to being farther away from the serving base station, experience worse coverage and radio channel conditions. Hence, we will focus first in this section on the worst 10th percentile values, which represent the conditions at the cell edge regions, thus reflecting the system coverage.

Figure 3 shows the indoor 10th-percentile values for received signal power (i.e., coverage) for macrocellular deployment with three intersite distances (i.e., ISD $1732 \mathrm{~m}$, ISD $866 \mathrm{~m}$, and ISD $433 \mathrm{~m}$ ). For each ISD, the femtocell penetration is varied from $0 \%$ (i.e., no femtocell deployment) to $100 \%$ (ultradense deployment of indoor femtocells, wherein each house has a femtocell deployed). As shown in the figure, the indoor coverage improves as the macrocell sites are densified from ISD $1732 \mathrm{~m}$ to ISD $433 \mathrm{~m}$. At lower femtocell penetration rate (i.e., from $0 \%$ to $25 \%$ ), difference in the indoor coverage is almost negligible. However, as we densify the femtocell penetration beyond $50 \%$, the coverage improvement starts to become more noticeable. The reason is due to the fact that as the femtocell penetration rate increases, the probability of femtocells at the cell edge houses increases accordingly. Due to being located indoors, femtocell can provide superior indoor coverage as compared to outdoor homogeneous macrocellular deployment. At 100\% penetration rate, the received signal level is constant over different ISDs, which means that the indoor is fully served 


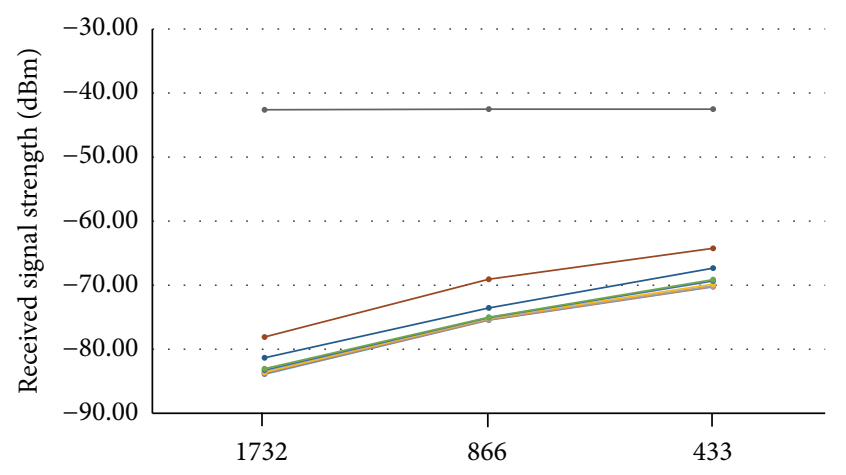

(m)

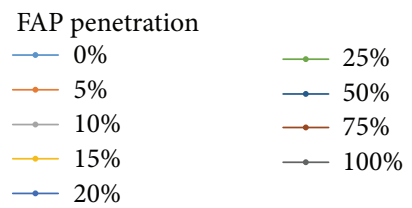

FIGURE 3: 10th-percentile (cell edge) values for received signal strength $(\mathrm{dBm})$, for macro-femto deployment with different femtocell penetration rates.

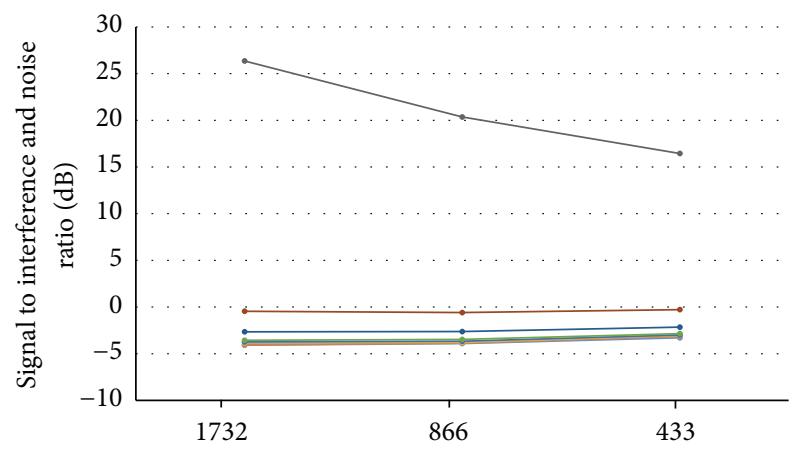

(m)

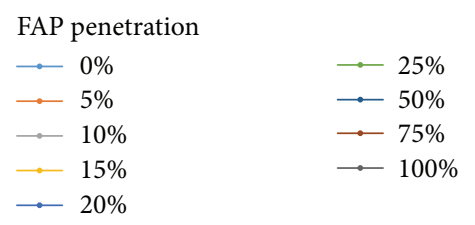

FIGURE 4: 10th-percentile (cell edge) values for signal to interference and noise ratio (SINR) (dB), for macro-femto deployment with different femtocell penetration rates.

by femtocell deployment (i.e., femtocells are more dominant than macrocells at the cell edge).

The corresponding radio channel conditions in terms of SINR for all deployment scenarios are shown in Figure 4. Intuitively, the SINR performance of homogeneous macrocellular deployment at the cell edge is quite poor. Although densified macro-only network (ISD $433 \mathrm{~m}$ ) should have relatively higher levels of SINR as compared to ISD $1732 \mathrm{~m}$, that does not happen due to the fact that higher macrocell density in this case causes excessive cochannel interference, which in turn degrades the radio channel conditions at the cell edge.

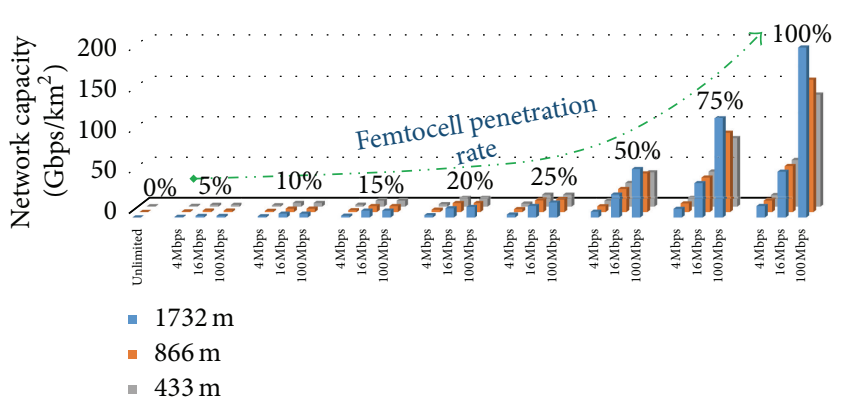

FIGURE 5: Average network capacity $\left(\mathrm{Gbps} / \mathrm{km}^{2}\right)$ for macro-femto cochannel deployment with different femtocell penetration rates (\%). The assumed operating bandwidth is $5 \mathrm{MHz}$.

The impact of deploying femtocells is quite negligible for lower femtocell penetration rate and starts to become more visible when penetration rate increases to $75 \%$. The reason is attributed to better coverage at the cell edge. Unlike dense macrocell configuration, the $100 \%$ femtocell penetration does not increase the interference level significantly. The signals coming from the cochannel femtocell interferers are attenuated a minimum of $60 \mathrm{~dB}$ due to the wall penetration losses. As such, the indoor femtocells APs, due to being located inside the residential houses, are well isolated from other cochannel femtocells, located in neighboring houses, which results in better radio channel conditions.

5.2. Capacity and Cost- and Energy-Efficiency Analysis. In this section we analyze the performance of heterogeneous macro-femto deployment, with varying femtocell penetration rates, in terms of average network area capacity and costefficiency and energy-efficiency. In the HetNet deployment, we consider three different backhaul connectivity speed constraints (i.e., $4 \mathrm{Mbps}, 16 \mathrm{Mbps}$, and $100 \mathrm{Mbps}$ ) for the femtocell access points, whereas for macrocellular sites no such limitation has been assumed (i.e., the backhaul connectivity speeds is virtually "unlimited"). Moreover, the carrier bandwidth is assumed to be $5 \mathrm{MHz}$.

Figure 5 shows the average indoor network capacity trend for macro-femto deployment. For each macrocellular intersite distance (ISD), femtocell penetration rate varies from $0 \%$ (i.e., no femtocell deployment at all) to $100 \%$ (i.e., every house has a femtocell deployed). As can be seen from the figure, the network capacity increases significantly as we start to deploy indoor femtocell access points. Table 8 compares the homogeneous macro-only deployment performance with heterogeneous macro-femto deployment. The femtocell penetration in this case is only 5\%; that is, only $5 \%$ of the houses in $1 \mathrm{~km}^{2}$ area have indoor femtocells deployed. Due to smaller coverage footprint, the $5 \%$ femtocell penetration rate results in cell density of $160 \mathrm{cells} / \mathrm{km}^{2}$. As we can see from the table, the heterogeneous deployment even in the worst case condition (i.e., femtocell backhaul limited to $4 \mathrm{Mbps}$ broadband connection) yields a network capacity of $0.63 \mathrm{Gbps} / \mathrm{km}^{2}$, which is $32 \mathrm{x}$ greater than the network capacity offered by the baseline ISD $1732 \mathrm{~m}$ macroonly network configuration (with no backhaul connectivity 
TABLE 8: Average network capacity at $5 \mathrm{MHz}$ bandwidth.

\begin{tabular}{lcc}
\hline Deployment strategy & Cell density $\left(\right.$ cells per $\left.\mathrm{km}^{2}\right)$ & Network capacity $\left(\mathrm{Gbps} / \mathrm{km}^{2}\right)$ \\
\hline Homogeneous (macro-only) & & \\
ISD $1732 \mathrm{~m}$-no B/H limitation & 3.5 & 0.02 \\
ISD $866 \mathrm{~m}$-no B/H limitation & 13.9 & 0.10 \\
ISD $433 \mathrm{~m}$-no B/H limitation & 55.4 & 0.43 \\
\hline Heterogeneous (macro-femto) & & 160 \\
ISD $1732 \mathrm{~m}$ (5\% femtopenetration): & 160 & 0.63 \\
$\quad$ (i) Femtocell B/H connectivity at $4 \mathrm{Mbps}$ & 160 & 1.68 \\
(ii) Femtocell B/H connectivity at $16 \mathrm{Mbps}$ & & 1.68 \\
$\quad$ (iii) Femtocell B/H connectivity at $100 \mathrm{Mbps}$ &
\end{tabular}

constraint). In contrast, the densest macro-only deployment with ISD of $433 \mathrm{~m}$ yields only $22 \mathrm{x}$ greater network capacity than the baseline configuration. Hence, it is concluded that even in worst case scenario, where the achievable cell level capacity of femtocell access points is limited by the backhaul, the indoor network capacity can be significantly increased by deploying more femtocell access points, as compared to densifying the outdoor macrolayer. The question, however, remains that how does the corresponding cost and energy consumption performance of macro-femto deployment compare with the homogeneous macro-only deployment. This is investigated next.

Starting with the cost-benefit analysis, Figure 6 shows the cost-efficiency for macro-femto deployment with varying femtocell penetration rate for each macrointersite distance (ISD). The cost-efficiency performance of macrofemto deployment follows the same trend as observed for average network capacity performance. Due to relatively lower power consumption per access point and higher value of network capacity gain, the cost-efficiency of macro-femto deployment increases with the femtocell penetration rate. Table 9 lists the total cost per area and cost-efficiency of homogeneous macro-only deployment and heterogeneous macro-femto deployment with a nominal penetration rate of $5 \%$. Although the total cost per area for macro-femto deployment is greater than that of the baseline configuration, the huge network capacity gain achieved through dense indoor femtocell deployment helps in offsetting the incurred total cost of deployment, thereby resulting in higher costefficiency. For example, in case of $4 \mathrm{Mbps}$ femtocell backhaul limitation, the cost-efficiency of macro-femto deployment is $4.4 \mathrm{x}$ greater than the baseline macro-only configuration with ISD $1732 \mathrm{~m}$. Subsequent densification of macrocell from ISD $1732 \mathrm{~m}$ to ISD $433 \mathrm{~m}$ leads to cell density of only 55.4 cells $/ \mathrm{km}^{2}$ but with a total cost of $1924 \mathrm{k} € / \mathrm{km}^{2}$, which is quite significant as compared to femtocell deployment with 160 cells $/ \mathrm{km}^{2}$ (i.e., $528 \mathrm{k} € / \mathrm{km}^{2}$ ).

From the energy-efficiency point of view, owing to the high capacity gains, the amount of bits transferred per $\mathrm{kW}$ is higher for macro-femto deployment. In other words, as the femtocell penetration increases, the energy consumption in transferring one bit of data goes down, as shown in Figure 7. Even for the case of nominal femtocell penetration of $5 \%$, the macro-femto deployment has lower overall area

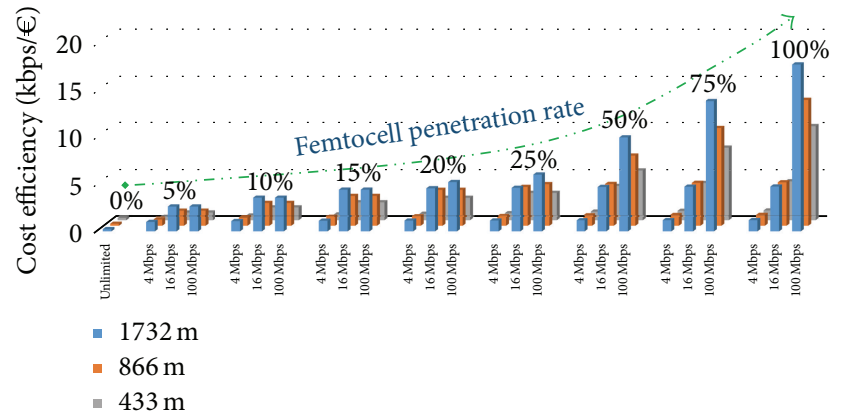

Figure 6: Cost-efficiency (kbps/€) for macro-femto cochannel deployment with different femtocell penetration rates (\%). The assumed operating bandwidth is $5 \mathrm{MHz}$.

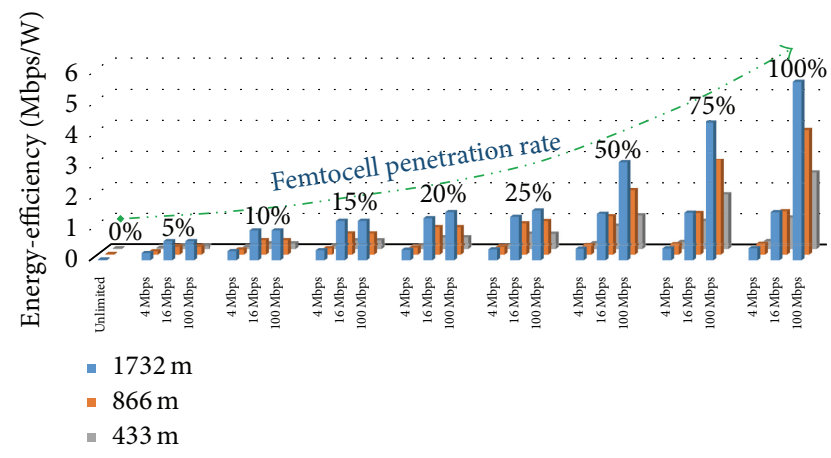

FIGURE 7: Energy-efficiency (Mbps/kW) for macro-femto cochannel deployment with different femtocell penetration rates (\%). The assumed operating bandwidth is $5 \mathrm{MHz}$.

power consumption and relatively higher energy-efficiency as compared to baseline macro-only scenario with ISD $1732 \mathrm{~m}$, as shown by the energy-efficiency comparison in Table 10.

5.3. Impact of Increasing the Operating Bandwidth. In the previous section, we observed that despite being limited by backhaul connectivity, femtocell based heterogeneous network offered significant indoor network capacity with substantially higher cost- and energy-efficiency, compared to homogeneous macrocellular densification with virtually "unlimited" backhaul. In this section we investigate a possible operator strategy of increasing the operating bandwidth 
TABLE 9: Cost-efficiency performance at $5 \mathrm{MHz}$ bandwidth.

\begin{tabular}{|c|c|c|c|}
\hline Deployment strategy & Cell density (cells per $\mathrm{km}^{2}$ ) & Total cost per area $\left(\mathrm{k} € / \mathrm{km}^{2}\right)$ & Cost-efficiency (kbps/€) \\
\hline \multicolumn{4}{|l|}{ Homogeneous (macro-only) } \\
\hline ISD $1732 \mathrm{~m}-$ no $\mathrm{B} / \mathrm{H}$ limitation & 3.5 & 121 & 0.23 \\
\hline ISD $866 \mathrm{~m}-$ no $\mathrm{B} / \mathrm{H}$ limitation & 13.9 & 482 & 0.21 \\
\hline ISD $433 \mathrm{~m}-$ no $\mathrm{B} / \mathrm{H}$ limitation & 55.4 & 1924 & 0.22 \\
\hline \multicolumn{4}{|l|}{ Heterogeneous (macro-femto) } \\
\hline \multicolumn{4}{|l|}{ ISD 1732 m (5\% femtopenetration): } \\
\hline (i) Femtocell $\mathrm{B} / \mathrm{H}$ connectivity at $4 \mathrm{Mbps}$ & 160 & 528 & 1.0 \\
\hline (ii) Femtocell $\mathrm{B} / \mathrm{H}$ connectivity at $16 \mathrm{Mbps}$ & 160 & 528 & 2.65 \\
\hline (iii) Femtocell B/H connectivity at $100 \mathrm{Mbps}$ & 160 & 528 & 2.65 \\
\hline
\end{tabular}

TABLE 10: Energy-efficiency performance at $5 \mathrm{MHz}$ bandwidth.

\begin{tabular}{|c|c|c|c|}
\hline Deployment strategy & Cell density (cells per $\mathrm{km}^{2}$ ) & Area power $\left(\mathrm{kW} / \mathrm{km}^{2}\right)$ & Energy-efficiency (Mbps/kW) \\
\hline \multicolumn{4}{|l|}{ Homogeneous (macro-only) } \\
\hline ISD $1732 \mathrm{~m}-$ no $\mathrm{B} / \mathrm{H}$ limitation & 3.5 & 1.2 & 0.23 \\
\hline ISD $866 \mathrm{~m}$-no $\mathrm{B} / \mathrm{H}$ limitation & 13.9 & 4.8 & 0.21 \\
\hline ISD $433 \mathrm{~m}-$ no $\mathrm{B} / \mathrm{H}$ limitation & 55.4 & 19.2 & 0.22 \\
\hline \multicolumn{4}{|l|}{ Heterogeneous (macro-femto) } \\
\hline \multicolumn{4}{|l|}{ ISD 1732 m (5\% femtopenetration) } \\
\hline (i) Femtocell $\mathrm{B} / \mathrm{H}$ connectivity at $4 \mathrm{Mbps}$ & 160 & 1.16 & 1.0 \\
\hline (ii) Femtocell $\mathrm{B} / \mathrm{H}$ connectivity at $16 \mathrm{Mbps}$ & 160 & 1.16 & 2.65 \\
\hline (iii) Femtocell $\mathrm{B} / \mathrm{H}$ connectivity at $100 \mathrm{Mbps}$ & 160 & 1.16 & 2.65 \\
\hline
\end{tabular}

of homogeneous macrocellular deployment and make a technoeconomic comparison with the heterogeneous macrofemto deployment scenario with $5 \mathrm{MHz}$ bandwidth. For the comparison, we again assume that the macrocell sites have no backhaul limitation, while the femtocell access points are backhaul limited.

For the homogeneous macrocellular deployment, we consider two carrier bandwidths: (i) $40 \mathrm{MHz}$ and (ii) $100 \mathrm{MHz}$. As radio spectrum is a scarce as well as priced resource, we additionally consider the cost of adding more spectrum bandwidth to the system. The spectrum value is usually driven by fierce competition among the stakeholders (usually mobile operators). In this paper, we assume the price of purchasing a unit spectrum bandwidth (in this case $1 \mathrm{MHz}$ ) in the $2 \mathrm{GHz}$ frequency band at $10 €$ per $\mathrm{km}^{2}$, that is, $10 € / \mathrm{MHz} / \mathrm{km}^{2}$, which is in line with spectrum value assumed in [39] for the spectrum at the $700 \mathrm{MHz}$ band. It is pertinent to note, however, that the value of the spectrum varies greatly between different regions and/or markets and also between different frequency bands. The value assumed here is anyway a realistic representative number and thus serves the analysis purposes well. The additional cost of increasing the bandwidth from $5 \mathrm{MHz}$ is $350 € / \mathrm{km}^{2}$ for $40 \mathrm{MHz}$ and $950 € / \mathrm{km}^{2}$ for $100 \mathrm{MHz}$ bandwidth. Table 11 gives the average network capacity and total cost per area for homogeneous macrocellular deployment with different operating bandwidths. As evident from the table, the network capacity increases with the increase in operating bandwidth. However, the increase in bandwidth comes with an additional spectrum cost in form of total area cost, $T_{\text {cost } / \mathrm{km}^{2}}$. For comparison, Table 12 provides the average network capacity and total cost per area for heterogeneous macro-femto deployment with different penetration rates, operating at nominal bandwidth of $5 \mathrm{MHz}$. By comparing the tables, it can be concluded that, at lower operating bandwidth ( $5 \mathrm{MHz})$, the femtocells can provide relatively higher network capacity and at lower cost as compared to macrocellular densification, even though the femtocells are backhaul limited. However, at the highest operating bandwidth $(100 \mathrm{MHz})$ and densest macrocellular configuration (ISD $433 \mathrm{~m}$ ), the average network capacity is approximately 9 Gbps. Achieving comparable network capacity gains with heterogeneous network deployment would require much higher femtocell deployment, if the femtocell backhaul connectivity is at 4 Mbps. This translates into more investment cost by the mobile operator in deploying thousands of femtocells per $\mathrm{km}^{2}$. However, with higher femtocell backhaul connectivity speeds, the same or even greater network capacity can be achieved with lower investment cost. For example, a network capacity of $10 \mathrm{Gbps} / \mathrm{km}^{2}$ can be achieved with $20 \%$ femtocell penetration and backhaul connectivity speed of $16 \mathrm{Mbps}$. The cost incurred in this case is $30 \%$ less than homogeneous macrocellular deployment with ISD $433 \mathrm{~m}$.

\section{Conclusion}

In this paper, we have analyzed and compared three different network evolution strategies based on (i) densification of homogeneous macro-only deployment, (ii) heterogeneous macro-femto network deployment with varying femtocell penetration rates, and (iii) macrocellular capacity enhancement 
TABLE 11: Capacity and cost performance of macro-only deployment with different bandwidths.

\begin{tabular}{|c|c|c|c|c|c|c|}
\hline \multirow[b]{2}{*}{ Macro-only } & \multicolumn{2}{|c|}{ Bandwidth $=5 \mathrm{MHz}$} & \multicolumn{2}{|c|}{ Bandwidth $=40 \mathrm{MHz}$} & \multicolumn{2}{|c|}{ Bandwidth $=100 \mathrm{MHz}$} \\
\hline & $\begin{array}{c}T_{\text {cost } / \mathrm{km}^{2}} \\
\left(\mathrm{k} € / \mathrm{km}^{2}\right)\end{array}$ & $\begin{array}{c}\bar{C}_{\text {net }} \\
\left(\mathrm{Gbps} / \mathrm{km}^{2}\right)\end{array}$ & $\begin{array}{c}T_{\text {cost } / \mathrm{km}^{2}} \\
\left(\mathrm{k} € / \mathrm{km}^{2}\right)\end{array}$ & $\begin{array}{c}\bar{C}_{\text {net }} \\
\left(\mathrm{Gbps} / \mathrm{km}^{2}\right)\end{array}$ & $\begin{array}{c}T_{\text {cost } / \mathrm{km}^{2}} \\
\left(\mathrm{k} € / \mathrm{km}^{2}\right)\end{array}$ & $\begin{array}{c}\bar{C}_{\text {net }} \\
\left(\mathrm{Gbps} / \mathrm{km}^{2}\right)\end{array}$ \\
\hline ISD $1732 \mathrm{~m}$ & 121 & 0.02 & 471 & 0.22 & 1071 & 0.56 \\
\hline ISD $866 \mathrm{~m}$ & 482 & 0.10 & 832 & 0.84 & 1382 & 2.10 \\
\hline ISD $433 \mathrm{~m}$ & 1924 & 0.43 & 2274 & 3.50 & 2874 & 8.75 \\
\hline
\end{tabular}

TABLE 12: Capacity and cost performance of macro-femto deployment at $5 \mathrm{MHz}$, with different femtocell penetration rates.

\begin{tabular}{lcccccc}
\hline $\begin{array}{l}\text { HetNet macro-femto } \\
\text { Macro ISD } 1732 \mathrm{~m}\end{array}$ & \multicolumn{2}{c}{ FAP penetration $5 \%$} & \multicolumn{2}{c}{ FAP penetration 20\% } & \multicolumn{2}{c}{ FAP penetration 75\% } \\
& $\begin{array}{c}T_{\text {cost } / \mathrm{km}^{2}} \\
\left(\mathrm{k} € / \mathrm{km}^{2}\right)\end{array}$ & $\begin{array}{c}\bar{C}_{\text {net }} \\
\left(\mathrm{Gbps} / \mathrm{km}^{2}\right)\end{array}$ & $\begin{array}{c}T_{\text {cost } / \mathrm{km}^{2}} \\
\left(\mathrm{k} € / \mathrm{km}^{2}\right)\end{array}$ & $\begin{array}{c}\bar{C}_{\text {net }} \\
\left(\mathrm{Gbps} / \mathrm{km}^{2}\right)\end{array}$ & $\begin{array}{c}T_{\text {cost } / \mathrm{km}^{2}} \\
\left(\mathrm{k} € / \mathrm{km}^{2}\right)\end{array}$ & $\begin{array}{c}\bar{C}_{\text {net }} \\
\left(\mathrm{Gbps} / \mathrm{km}^{2}\right)\end{array}$ \\
\hline (i) B/H at $4 \mathrm{Mbps}$ & 528 & 0.63 & 2076 & 2.51 & 7745 & 9.4 \\
(ii) B/H at $16 \mathrm{Mbps}$ & 528 & 1.68 & 2076 & 10.1 & 7745 & 37.6 \\
(iii) B/H at $100 \mathrm{Mbps}$ & 528 & 1.68 & 2076 & 11.5 & 7745 \\
\hline
\end{tabular}

with larger bandwidth. Both technical and economical aspects of the considered strategies were analyzed from an indoor service provisioning perspective. The main objective of this research work was to provide new insight into the technoeconomical aspects of different network capacity enhancing schemes and thus come up with recommendations and tools that can assist mobile operators in deciding the best network evolution strategy for their network in the future.

Three key performance metrics were considered in the analysis, namely, network capacity, and cost- and energyefficiency. In the analysis the femtocells penetration rate was varied from $0 \%$ (no femtocell deployed) to $100 \%$ (wherein every house had its own femtocell deployed). Moreover, three different broadband connectivity speeds for femtocell backhaul were considered. It was observed that, owing to the extremely high spatial reuse coupled with low power consumption and low cost per femtocell access points, the femtocell based HetNet solution offered higher overall indoor network area capacity and energy- and cost-efficiency for indoor service provisioning. However, the performance of femtocells can be largely limited by the backhaul data rates. As an outcome, the following main conclusions can be drawn:

(i) Small cell solutions can offer higher network capacity in a cost- and energy-efficient manner, given that they have higher backhaul connectivity to the core network.

(ii) Moreover, instead of increasing the carrier bandwidth, the mobile operators can initially enhance the capacity of their network by deploying small base stations and then gradually increase the spectrum bandwidth for their networks.

For the 5G and beyond mobile networks, we envision that mobile operators will have to rely on a combination of capacity enhancing techniques. Ultradense deployment of small cells together with larger bandwidth, mainly through carrier aggregation, will form an integral part of their network evolution strategies.

In general, the cost-efficiency analysis in this paper is based on simple cost model assuming Greenfield deployment. In practice, however, the cost modeling can be much more complex; for example, (i) operators may already have some site assets, from their existing legacy networks, which they can capitalize on and (ii) operators might get into an agreement with other operators over site sharing or even spectrum sharing in order to enhance their capacity. Further studies will concentrate on a much more detailed technoeconomic modeling that take into account the different deployment aspects as found in practice. From spectrum management point of view, it will also be interesting to analyze the deployment case of dividing the spectrum between macro- and femtocells, that is, using adjacent channels for different layers of HetNet in order to eliminate the interlayer interference. Furthermore, it is pertinent to note that the distribution of traffic in this paper was considered to be homogeneous (i.e., uniformly distributed) in the indoor locations and it was assumed that all the users are generating high traffic demand. In real life, however, such an extreme condition might not be realizable. The traffic across real networks is nonuniformly distributed and the HetNets are deployed in only hotspot areas where there is high capacity demand. This results in lower investments by the operator as well as lower energy consumption. A sequel to this paper will focus on nonuniform traffic distribution and will analyze the performance trends of macro-femtocell deployment, with varying backhaul constraints, with pure macrocellular densification. Furthermore, it is to be acknowledged that the analysis principles adopted in this paper focus solely on the network level capacity of different deployment solutions without explicitly considering the radio resource management aspects. Hence, in true multiuser networks where the capacity of a single network element or access point is divided between the multiple simultaneously scheduled 
devices, the UE level capacity will naturally be smaller. In any case, the provided analysis results and adopted analysis methodology provide valuable understanding and insight of the network level capacity limits of different alternative deployment solutions when pushed to their ultimate limits.

To summarize, the analysis principles and methodologies offered in this paper will provide valuable tools for the network vendors and operators to carry out detailed technoeconomical planning and optimization for the mobile network evolution.

\section{Competing Interests}

The authors declare that they have no competing interests.

\section{Acknowledgments}

The authors would like to extend their gratitude to the Finnish Funding Agency for Technology and Innovation, TEKES, for funding this research work as a part of "EnergyEfficient Wireless Networks and Connectivity of DevicesSystems (EWINE-S)" Project.

\section{References}

[1] J. Zander, "Challenge 2020: 1000 times more capacity at todays cost \& energy," 2012, http://zandercom.com/web/wp-content/ uploads/2014/06/Challenges2020_Yonsei.pdf.

[2] Nokia, "Enhance mobile networks to deliver 1000 times more capacity by 2020," White Paper, Nokia Networks, 2014.

[3] Trends in Telecommunication Reform 2015: Getting ready for the digital economy, Report, International Telecommunications Union-Development Sector (ITU-D), 2015.

[4] V. H. MacDonald, "Advanced mobile phone service: the cellular concept," The Bell System Technical Journal, vol. 58, no. 1, pp. 1541, 1979.

[5] P.-H. Lehne, "3rd nordic workshop of system \& network optimization (snow)," in Proceedings of the Mobile Network Operator Challenges to Meet Future Demand for Mobile Broadband, April 2012.

[6] M. Paolini, "Mobile data move indoors," Mobile Europe, vol. 215, pp. 22-25, 2011.

[7] European Commission, "EU Commissioner calls on ICT industry to reduce its carbon footprint by $20 \%$ as early as 2015 ," March 2009, http://europa.eu/rapid/press-release MEMO-09140 en.htm.

[8] A. Asp, Y. Sydorov, M. Valkama, and J. Niemelä, "Radio signal propagation and attenuation measurements for modern residential buildings," in Proceedings of the IEEE Globecom Workshops (GC Wkshps '12), pp. 580-584, Anaheim, Calif, USA, December 2012.

[9] A. Asp, Y. Sydorov, M. Keskikastari, M. Valkama, and J. Niemelä, "Impact of modern construction materials on radio signal propagation: practical measurements and network planning aspects," in Proceedings of the 79th IEEE Vehicular Technology Conference (VTC '14-Spring), pp. 1-7, Seoul, Republic of Korea, May 2014.

[10] State of the Internet, Q2 Report, Akamai Technologies, Cambridge, Mass, USA, 2015.
[11] M. Z. Shakir and M.-S. Alouini, "On the area spectral efficiency improvement of heterogeneous network by exploiting the integration of macro-femto cellular networks," in Proceedings of the IEEE International Conference on Communications (ICC '12), pp. 5695-5700, Ottawa, Canada, June 2012.

[12] J. Markendahl and Ö. Mäkitalo, "A comparative study of deployment options, capacity and cost structure for macrocellular and femtocell networks," in Proceedings of the IEEE 21st International Symposium on Personal, Indoor and Mobile Radio Communications Workshops (PIMRC '10), pp. 145-150, September 2010.

[13] A. A. Widaa, J. Markendahl, and A. Ghanbari, "Toward capacity-efficient, cost-efficient and power-efficient deployment strategy for indoor mobile broadband," in Proceedings of the 24th European Regional Conference of the International Telecommunications Society, October 2013.

[14] Z. Frias and J. Pérez, "Techno-economic analysis of femtocell deployment in long-term evolution networks," Eurasip Journal on Wireless Communications and Networking, vol. 2012, article 288, 2012.

[15] R. Alkhansa, H. Artail, and D. M. Gutierrez-Estevez, "LTE-wifi carrier aggregation for future $5 \mathrm{G}$ systems: a feasibility study and research challenges," Procedia Computer Science, vol. 34, pp. 133-140, 2014.

[16] S. Tombaz, Z. Zheng, and J. Zander, "Energy efficiency assessment of wireless access networks utilizing indoor base stations," in Proceedings of the IEEE 24th Annual International Symposium on Personal, Indoor, and Mobile Radio Communications (PIMRC '13), pp. 3105-3110, London, UK, September 2013.

[17] S. F. Yunas, J. Niemelä, M. Valkama, and T. Isotalo, “Technoeconomical analysis and comparison of legacy and ultra-dense small cell networks," in Proceedings of the 39th Annual IEEE Conference on Local Computer Networks (LCN '14), pp. 768-776, Edmonton, Canada, September 2014.

[18] J. Itkonen, B. Tuzson, and J. Lempiäinen, "Assessment of network layouts for CDMA radio access," Eurasip Journal on Wireless Communications and Networking, vol. 2008, Article ID 259310, 2008.

[19] J. Lempiäinen and M. Manninen, Radio Interface System Planning for GSM/GPRS/UMTS, Kluwer Academic, 2001.

[20] M. J. Nawrocki, M. Dohler, and A. H. Aghvami, Understanding UMTS Radio Network Planning, John Wiley \& Sons, New York, NY, USA, 2006.

[21] W. Jianhui and Y. Dongfeng, "Antenna downtilt performance in urban environments," in Proceedings of the 1996 15th Annual Military Communications Conference (MILCOM '96), vol. 3, pp. 739-744, October 1996.

[22] R. Wahl and G. Wölfle, "Combined urban and indoor network planning using the dominant path propagation model," in Proceedings of the 1st European Conference on Antennas and Propagation (EuCAP '06), pp. 1-6, Nice, France, November 2006.

[23] R. Wahl, G. Wölfle, P. Wertz, and F. Landstorfer, "Dominant path prediction model for urban scenarios," in Proceedings of the 14th IST Mobile and Wireless Communications Summit, Dresden, Germany, June 2005.

[24] G. Woelfle and F. M. Landstorfer, "Dominant paths for the field strength prediction," in Proceedings of the 48th IEEE Vehicular Technology Conference (VTC '98), pp. 552-556, May 1998.

[25] F. Gunnarsson, M. Johansson, A. Furuskar et al., "Downtilted base station antennas-a simulation model proposal and 
impact on HSPA and LTE performance," in Proceedings of the IEEE 68th Vehicular Technology Conference (VTC '08), pp. 1-5, Calgary, Canada, September 2008.

[26] S. F. Yunas, T. Isotalo, J. Niemela, and M. Valkama, "Impact of macrocellular network densification on the capacity, energy and cost efficiency in dense urban environment," International Journal of Wireless \& Mobile Networks (IJWMN), vol. 5, no. 5, pp. 99-118, 2013.

[27] S. F. Yunas, A. Asp, J. Niemelä, and M. Valkama, "Deployment strategies and performance analysis of Macrocell and Femtocell networks in suburban environment with modern buildings," in Proceedings of the 39th Annual IEEE Conference on Local Computer Networks (LCN '14), pp. 643-651, Edmonton, Canada, September 2014.

[28] L. M. Correia, D. Zeller, O. Blume et al., "Challenges and enabling technologies for energy aware mobile radio networks," IEEE Communications Magazine, vol. 48, no. 11, pp. 66-72, 2010.

[29] M. Deruyck, W. Joseph, and L. Martens, "Power consumption model for macrocell and microcell base stations," Transactions on Emerging Telecommunications Technologies, vol. 25, no. 3, pp. 320-333, 2014.

[30] M. Deruyck, E. Tanghe, W. Joseph, and L. Martens, "Modelling and optimization of power consumption in wireless access networks," Computer Communications, vol. 34, no. 17, pp. 20362046, 2011.

[31] M. Deruyck, E. Tanghe, W. Joseph et al., "Model for power consumption of wireless access networks," IET Science, Measurement and Technology, vol. 5, no. 4, pp. 155-161, 2011.

[32] C. Hsia, D. F. Kimball, S. Lanfranco, and P. M. Asbeck, "Wideband high efficiency digitally-assisted envelope amplifier with dual switching stages for radio base-station envelope tracking power amplifiers," in Proceedings of the IEEE MTT-S International Microwave Symposium Digest (MTT '10), pp. 672-675, May 2010.

[33] Y.-C. Wu, K. Chen, E. J. Naglich, and D. Peroulis, "A wideband $0.7-2.2 \mathrm{GHz}$ tunable power amplifier with over $64 \%$ efficiency based on high-Q second harmonic loading," in Proceedings of the IEEE MTT-S International Microwave Symposium Digest (MTT '13), pp. 1-4, Seattle, Wash, USA, June 2013.

[34] NSN Flexi Compact Base Station, Datasheet, Nokia Networks and Solutions, https://networks.nokia.com/products/fleximultiradio-10-base-station.

[35] M. Deruyck, D. De Vulder, W. Joseph, and L. Martens, "Modelling the power consumption in femtocell networks," in Proceedings of the IEEE Wireless Communications and Networking Conference Workshops (WCNCW '12), pp. 30-35, Paris, France, April 2012.

[36] T. Smura, Techno-economic modelling of wireless network and industry architectures [Ph.D. dissertation], Aalto University, 2012.

[37] K. Johansson, A. Furuskär, P. Karlsson, and J. Zander, "Relation between base station characteristics and cost structure in cellular systems," in Proceedings of the IEEE 15th International Symposium on Personal, Indoor and Mobile Radio Communications (PIMRC '04), pp. 2627-2631, September 2004.

[38] J. Niemelä and T. Isotalo, "Coverage constrained technoeconomical comparison of macro and small cell planning strategies," Internal Report, Department of Electronics and Communications Engineering, Tampere University of Technology, 2014.
[39] V. Nikolikj and T. Janevski, "A cost modeling of high-capacity LTE-advanced and IEEE 802.11ac based heterogeneous networks, deployed in the $700 \mathrm{MHz}, 2.6 \mathrm{GHz}$ and $5 \mathrm{GHz}$ Bands," Procedia Computer Science, vol. 40, pp. 49-56, 2014. 

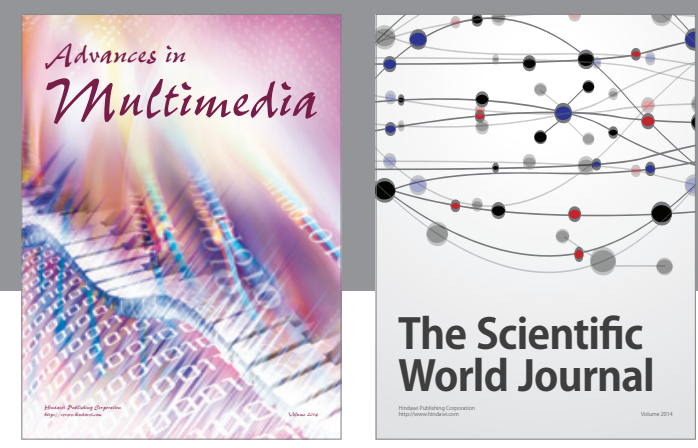

The Scientific World Journal
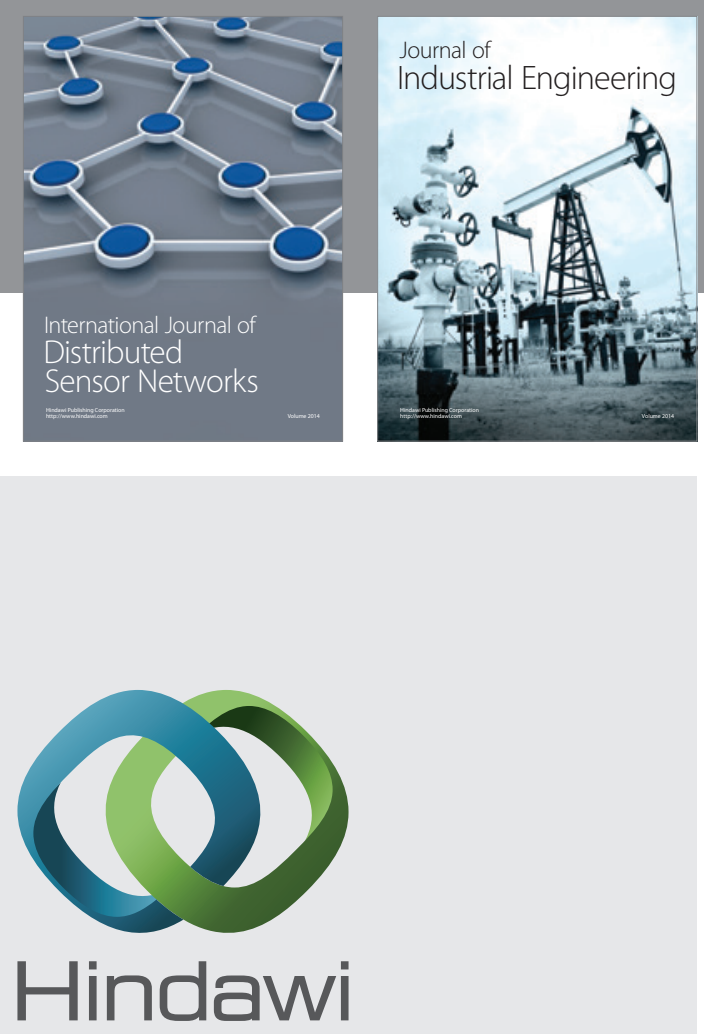

Submit your manuscripts at

http://www.hindawi.com

\section{Computer Networks} and Communications
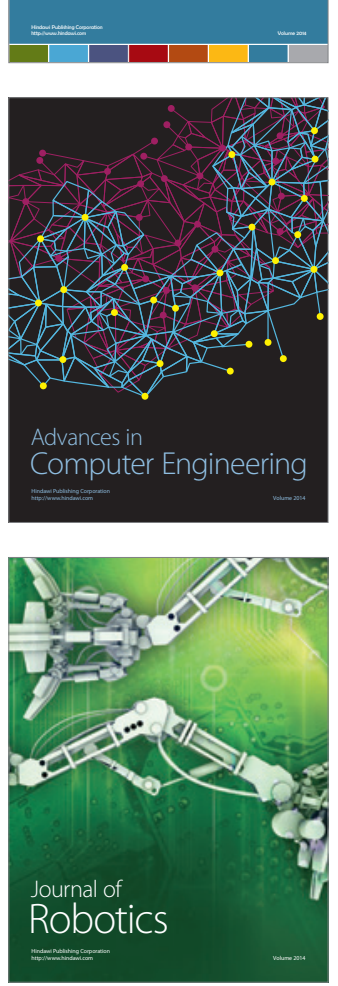
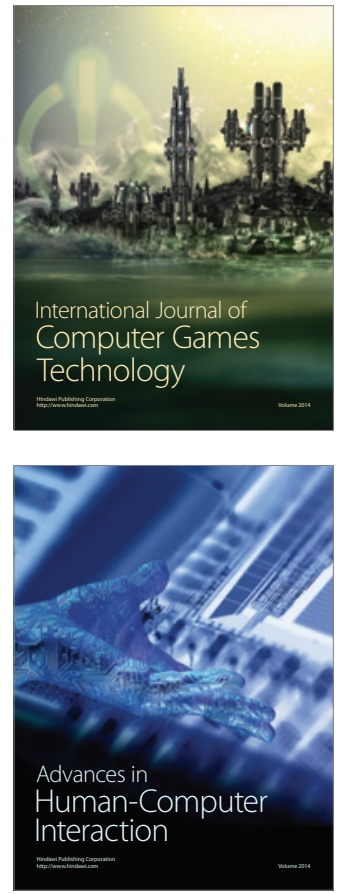
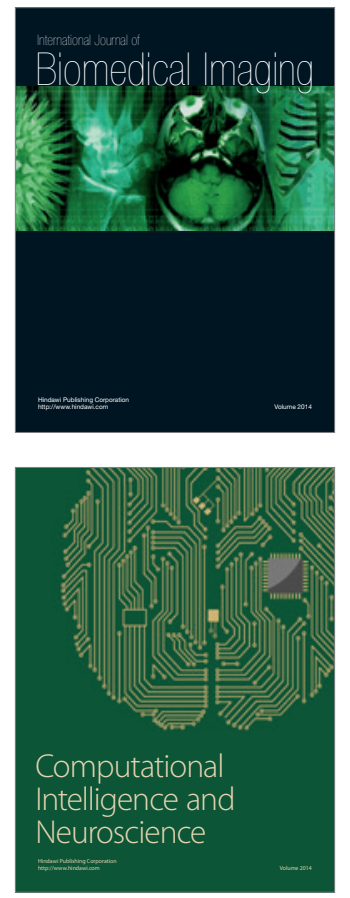
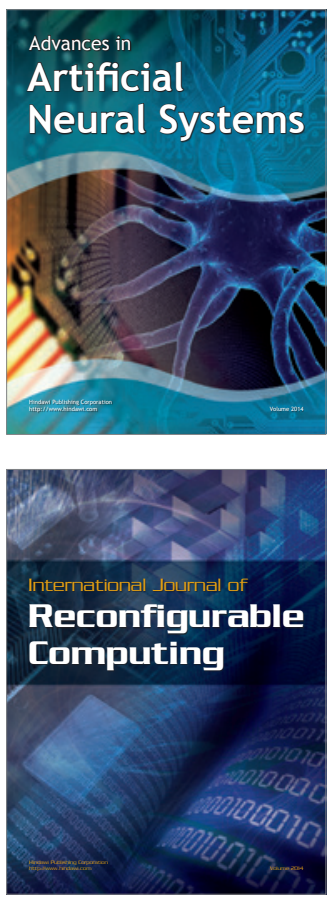
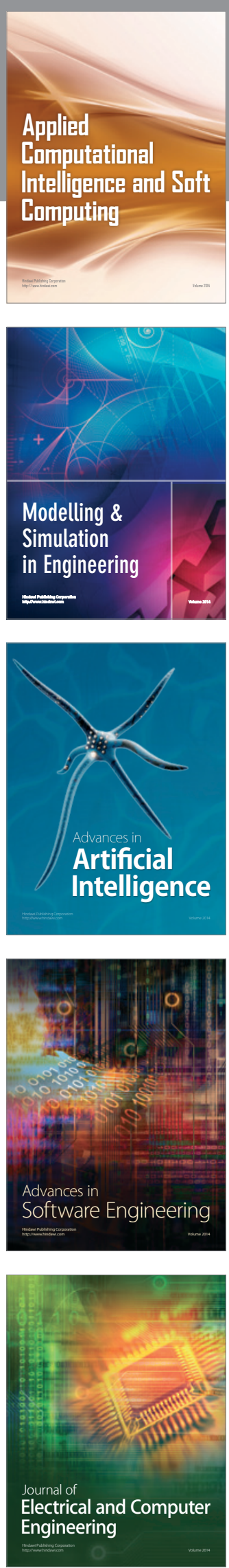